\title{
BMJ Open Inconvenient relationship of haemoglobin A1c level with endothelial function in type 2 diabetes in a cross-sectional study
}

Takayuki Yamaji, ${ }^{1}$ Takahiro Harada, ${ }^{1}$ Yu Hashimoto, ${ }^{1}$ Yuji Takaeko, ${ }^{1}$ Masato Kajikawa, ${ }^{2}$ Yiming Han, ${ }^{1}$ Tatsuya Maruhashi, ${ }^{3}$ Shinji Kishimoto, ${ }^{3}$ Haruki Hashimoto, ${ }^{1}$ Yasuki Kihara, ${ }^{1}$ Eisuke Hida, ${ }^{4}$ Kazuaki Chayama, ${ }^{5}$ Chikara Goto, ${ }^{6}$ Farina Mohamad Yusoff, ${ }^{3}$ Ayumu Nakashima, ${ }^{7}$ Yukihito Higashi (1) ${ }^{2,3}$

To cite: Yamaji T, Harada T, Hashimoto $\mathrm{Y}$, et al. Inconvenient relationship of haemoglobin A1C level with endothelial function in type 2 diabetes in a crosssectional study. BMJ Open 2021;11:e045415. doi:10.1136/ bmjopen-2020-045415

- Prepublication history and additional supplemental material for this paper are available online. To view these files, please visit the journal online (http://dx.doi.org/10.1136/ bmjopen-2020-045415)

Received 01 October 2020 Accepted 18 May 2021

Check for updates

(C) Author(s) (or their employer(s)) 2021. Re-use permitted under CC BY-NC. No commercial re-use. See rights and permissions. Published by BMJ.

For numbered affiliations see end of article.

Correspondence to Professor Yukihito Higashi; yhigashi@hiroshima-u.ac.jp

\section{ABSTRACT}

Objective The aim of this study was to determine the relationship of haemoglobin $\mathrm{A} 1 \mathrm{c}(\mathrm{HbA1c})$ level with flowmediated vasodilation (FMD) and nitroglycerine-induced vasodilation (NID) in patients with type 2 diabetes.

Design Cross-sectional study.

Setting 22 university hospitals and affiliated clinics in Japan.

Participants 1215 patients with type 2 diabetes including 349 patients not taking antidiabetic drugs.

Measures We evaluated FMD and HbA1c level. All patients were divided into four groups based on $\mathrm{HbA} 1 \mathrm{C}$ level: $<6.5 \%, 6.5 \%-6.9 \%, 7.0 \%-7.9 \%$ and $\geq 8.0 \%$. Results An inverted U-shaped pattern of association between $\mathrm{HbA} 1 \mathrm{c}$ level and FMD was observed at the peak of $\mathrm{HbA} 1 \mathrm{c}$ of about $7 \%$. FMD was significantly smaller in the $\mathrm{HbA} 1 \mathrm{c}<6.5 \%$ group than in the $\mathrm{HbA} 1 \mathrm{c} 6.5 \%-6.9 \%$ group and $\mathrm{HbA} 1 \mathrm{c} 7.0 \%-7.9 \%$ group $(\mathrm{p}<0.001$ and $\mathrm{p}<0.001$ ), and FMD values were similar in the $\mathrm{HbA1C}$ $<6.5 \%$ group and $\mathrm{HbA} 1 \mathrm{c} \geq 8.0 \%$ group. There were no significant differences in NID values among the four groups. After adjustments for confounding factors, FMD was significantly smaller in the $\mathrm{HbA} 1 \mathrm{C}<6.5 \%$ group than in the $\mathrm{HbA} 1 \mathrm{c} 6.5 \%-6.9 \%$ and $\mathrm{HbA} 1 \mathrm{c} 7.0 \%-7.9 \%$ group $(p=0.002$ and $p=0.04)$. In patients not taking antidiabetic drugs, FMD was also significantly smaller in the $\mathrm{HbA1C}$ $<6.5 \%$ group than in the $\mathrm{HbA} 1 \mathrm{c} 6.5 \%-6.9 \%$ group and HbA1c $7.0 \%-7.9 \%$ group ( $<<0.001$ and $p=0.02$ ), and there were no significant differences in NID values among the four groups.

Conclusions These findings suggest that there is an inverted U-shaped pattern of association between FMD and $\mathrm{HbA} 1 \mathrm{C}$ and that a low $\mathrm{HbA} 1 \mathrm{c}$ level of $<6.5 \%$ is associated with endothelial dysfunction.

Trial registration number UMIN000012950, UMIN000012951, UMIN000012952 and UMIN000003409.

\section{INTRODUCTION}

Diabetes is a risk factor for atherosclerosis and subsequent cardiovascular disease (CVD) and cardiovascular events. ${ }^{1}$ Previous studies showed that adults with diabetes have twofold to fourfold higher rates of all-cause mortality and CVD
Strengths and limitations of this study

- The present study showed the relationship between haemoglobin A1c and flow-mediated vasodilation in patients with type 2 diabetes.

- The present study was conducted in multiple centres and had a large sample size.

We did not have information on the duration of diabetes from onset.

- This study was a cross-sectional study and we were therefore not able to evaluate the causality between low haemoglobin A1c level and flow-mediated vasodilation.

mortality than in subjects without diabetes. ${ }^{23}$ Therefore, prevention of CVD in patients with diabetes is clinically important. Haemoglobin A1c (HbA1c) level, an index of glycaemic control, is usually checked in patients with diabetes. However, HbAlc-guided diabetes treatment is still controversial.

Previous large clinical trials, including the Veterans Affairs Diabetes Trial (VADT), the Action in Diabetes and Vascular Disease: Preterax and Diamicron MR Controlled Evaluation (ADVANCE) trial, and the Kumamoto Study, have shown that intensive glucose control reduces the incidence of microvascular diseases such as retinopathy and nephropathy, but not the incidence of macrovascular diseases such as myocardial infarction and stroke in patients with type 2 diabetes. ${ }^{4-7}$ The Action to Control Cardiovascular Risk in Diabetes (ACCORD) trial showed that intensive therapy increased all-cause mortality in patients with type 2 diabetes. ${ }^{8}$ The VADT and ADVANCE trials showed that severe hypoglycaemia increases death from CVD and any cause of death. ${ }^{5}$ Unfortunately, the optimal target level of HbAlc in diabetes is unclear, and 
it is still controversial whether intensive glucose control by HbAlc-guided therapy reduces the incidence of cardiovascular events. ${ }^{578}$

Endothelial dysfunction is well known as the initial step of atherosclerosis and plays a critical role in the development of atherosclerosis, leading to CVD. ${ }^{9}$ Measurement of flowmediated vasodilation (FMD) in the brachial artery is an established tool for assessment of endothelial function, ${ }^{10}$ and it is well known as an independent predictor of cardiovascular events. ${ }^{11}$ Endothelial function assessed by FMD is impaired by traditional cardiovascular risk factors such as hypertension, dyslipidaemia, smoking, chronic alcohol drinking and also diabetes. ${ }^{12}$ FMD is reversible by several interventions such as lifestyle modifications and pharmacological treatment. ${ }^{13} 14$ Therefore, FMD is a very useful tool for assessing current vascular function and cardiovascular risk.

Diabetes is associated with endothelial dysfunction. ${ }^{15} 16$ Chronic hyperglycaemia is a major contributor to increased oxidative stress and causes endothelial dysfunction through inactivation of nitric oxide. ${ }^{17}$ Several studies have shown that endothelial function is improved by antidiabetic therapy, including use of antidiabetic drugs. ${ }^{13} 1819$ However, there is little information on the relationship between $\mathrm{HbAlc}$ level and endothelial function.

Therefore, we evaluated the relationship between HbA1c level and endothelial function assessed by FMD in patients with type 2 diabetes.

\section{METHODS}

\section{Study patients}

A total of 10260 subjects (7385 patients from the Flowmediated Dilation-Japan (FMD-J) study and 2875 patients who underwent a health check-up at Hiroshima University Hospital between August 2007 and August 2016) were recruited in this study. The FMD-J study was a prospective multicentre registry. The design of the FMD-J study has been described in detail previously. ${ }^{20}$ The protocol used for measurement of FMD was the same as in the FMD-J study and at Hiroshima University Hospital. Exclusion criteria are shown in online supplemental figure 1. Finally, we enrolled 1215 subjects in this study. Hypertension was defined as use of antihypertensive drugs or systolic blood pressure of more than $140 \mathrm{~mm} \mathrm{Hg}$ or diastolic blood pressure of more than $90 \mathrm{~mm} \mathrm{Hg}$ measured in a sitting position on at least three occasions. Dyslipidaemia was defined according to the third report of the National Cholesterol Education Program. ${ }^{21}$ Diabetes was defined according to the American Diabetes Association recommendation. ${ }^{22}$ Smokers were defined as those who were current smokers. CVD was defined as coronary heart disease and cerebrovascular disease. Coronary heart disease included angina pectoris, prior myocardial infarction and unstable angina. Cerebrovascular disease included ischaemic stroke, haemorrhagic stroke and transient ischaemic attack. Written informed consent for participation in this study was obtained from all participants. All methods were performed in accordance with the relevant guidelines and regulations.
Study 1: HbA1c level and vascular function in patients with type 2 diabetes

In study 1, we assessed the relationships between HbAlc level and vascular function as assessed by measurement of FMD, an index of endothelium-dependent vasodilation, and by measurement of nitroglycerine-induced vasodilation (NID), an index of endothelium-independent vasodilation, in 1215 patients with type 2 diabetes. First, we divided the patients into two groups based on their HbA1c level: $<6.5 \%$ and $\geq 6.5 \%$. Multivariate regression analysis was performed to identify independent variables associated with vascular function. Next, we divided the patients into four groups according to HbAlc level: $<6.5 \%, 6.5 \%-6.9 \%, 7.0 \%-7.9 \%$ and $\geq 8.0 \%$. We next assessed the relationships of HbA1c levels with FMD and NID using propensity score matching.

\section{Study 2: HbA1c level and vascular function in patients with type 2 diabetes not taking antidiabetic drugs}

We evaluated the relationship of HbAlc level with FMD and NID in 349 patients with type 2 diabetes who were not taking antidiabetic drugs by using the same protocol as that used in study 1 .

\section{Measurements of FMD and NID}

High-resolution ultrasonography equipment specialised to measure FMD (UNEXEF18G, UNEX, Nagoya, Japan) was used to evaluate FMD. Additional details are available in the online supplemental methods. The intraclass correlation coefficient between each of the participating institutions and the core laboratory has been previously described. ${ }^{23}$

\section{Statistical analysis}

Results are presented as mean \pm SD. All reported probability values were two-sided and a probability value of $<0.05$ was considered statistically significant. An association between FMD and HbA1c level was explored visually using a locally weighted regression smoothing (Lowess) plot. Categorical values were compared by means of $\chi^{2}$ test. Continuous variables were compared using analysis of variance (ANOVA) multiple groups. Comparisons between the groups categorised according to HbAlc level were carried out using repeated measures ANOVA with Tukey's post-hoc test. Univariate linear regression analyses were performed to assess the relationships among the variables. Multivariate logistic regression analysis was performed to identify independent variables associated with lower quartiles of FMD $(<2.1 \%)$ and NID $(<6.2 \%)$. Age, gender, body mass index (BMI), creatinine levels, current smoking, and the presence of hypertension, dyslipidaemia and CVD were entered into the multivariate logistic regression analysis. As a sensitivity analysis, propensity score analysis was used to minimise the selection bias for evaluation of the relationship between HbAlc level and vascular function. The propensity score was calculated for each patient on the basis of logistic regression analysis of the probability of not taking antidiabetic drugs within groups stratified by HbAlc level $(<6.5 \%, 6.5 \%-6.9 \%, 7.0 \%-7.9 \%$ and $\geq 8.0 \%)$ using clinical 
Table 1 Clinical characteristics of patients with type 2 diabetes

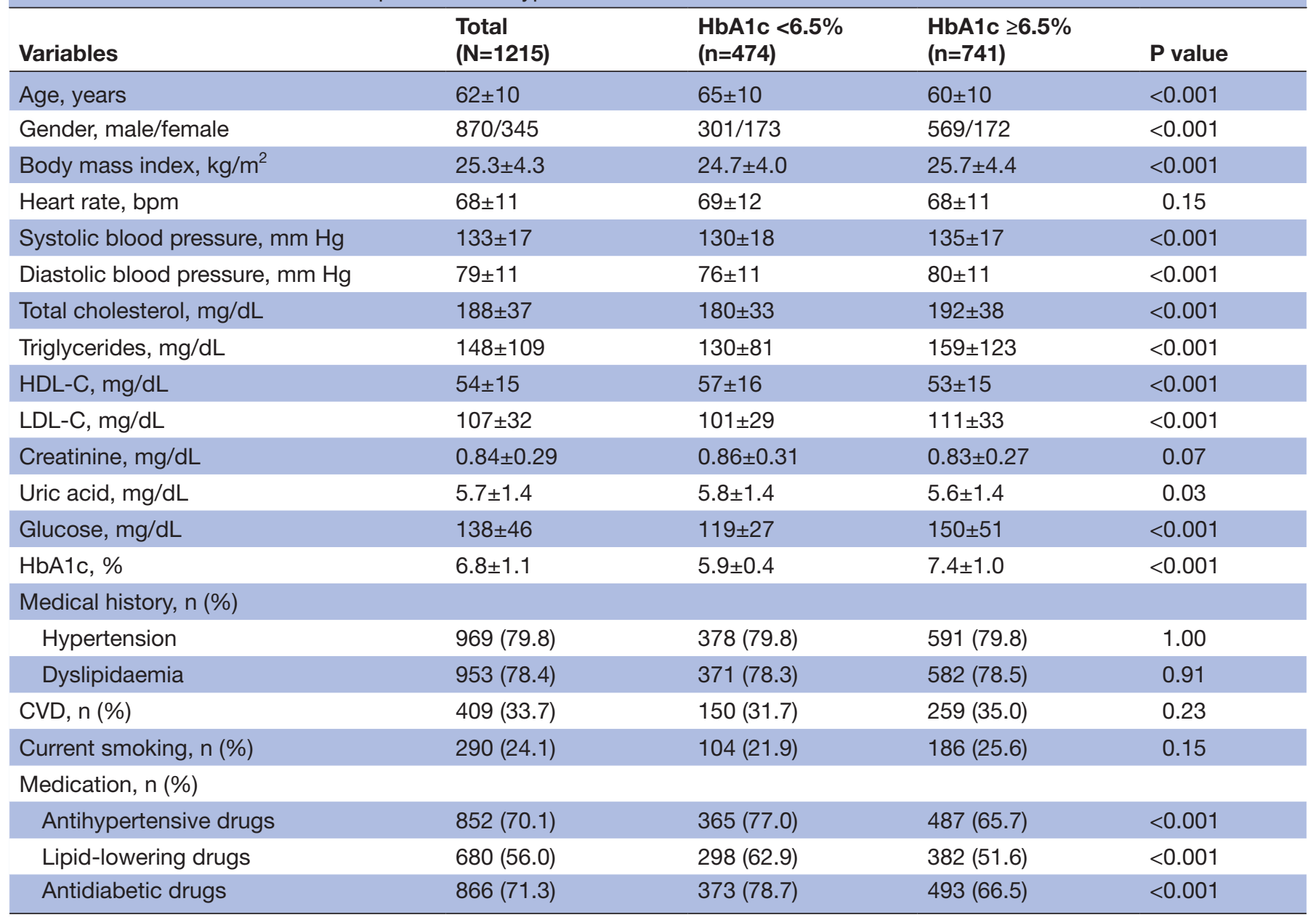

bpm, beats per minute; CVD, cardiovascular disease; HbA1c, haemoglobin A1c; HDL-C, high-density lipoprotein cholesterol; LDL-C, lowdensity lipoprotein cholesterol.

variables including age, sex, BMI, systolic blood pressure, diastolic blood pressure, heart rate, total cholesterol, triglycerides, high-density lipoprotein (HDL) cholesterol, uric acid levels, current smoking (yes or no), medication with antihypertensive drugs (yes or no), medication with lipid-lowering drugs (yes or no) and presence of CVD (yes or no). With these propensity scores using a calliper width of $0.25 \mathrm{SD}$ of the logit of the propensity score, two well-matched groups based on clinical characteristics were created for comparison of the prevalence of endothelial dysfunction defined as FMD of $<2.1 \%$, the division point for the lowest quartile of FMD in all participants. All data were processed using JMP Pro V.14.0 software (SAS Institute, Cary, North Carolina, USA).

\section{RESULTS}

\section{Study 1}

Relationships between $\mathrm{HbA1c}$ level and variables in patients with type 2 diabetes

The baseline characteristics of the 1215 patients are summarised in table 1 . The mean FMD value was $4.2 \% \pm 2.8 \%$ and the mean NID value was $10.6 \% \pm 5.8 \%$.
The baseline characteristics of subjects with HbA1c $<6.5 \%$ and those with $\mathrm{HbAlc} \geq 6.5 \%$ are also summarised in table 1. FMD was significantly smaller in the HbAlc $<6.5 \%$ group than in the $\mathrm{HbA} 1 \mathrm{c} \geq 6.5 \%$ group $(3.5 \% \pm 2.7 \%$ and $4.6 \% \pm 2.7 \%$, respectively, $\mathrm{p}<0.001$; figure $1 \mathrm{~A}$ ). NID values were similar in the two groups $(10.6 \% \pm 5.8 \%$ in the HbAlc $<6.5 \%$ group and $10.8 \% \pm 5.6 \%$ in the HbAlc $\geq 6.5 \%$ group, $\mathrm{p}=0.73$; figure $1 \mathrm{~B}$ ).

Next, the patients were divided into four groups based on HbA1c level: $<6.5 \%, 6.5 \%-6.9 \%, 7.0 \%-7.9 \%$ and $\geq 8.0 \%$. The baseline characteristics are summarised in online supplemental table 1 . FMD values were $3.5 \% \pm 2.7 \%$ in the $\mathrm{HbA1c}<6.5 \%$ group, $4.8 \% \pm 2.9 \%$ in the HbAlc $6.5 \%-6.9 \%$ group, $4.5 \% \pm 2.6 \%$ in the HbA1c $7.0 \%-7.9 \%$ group, and $4.2 \% \pm 2.7 \%$ in the $\mathrm{HbAlc} \geq 8.0 \%$ group $(\mathrm{p}<0.001)$. FMD was significantly smaller in the HbAlc $<6.5 \%$ group than in the HbAlc $6.5 \%-6.9 \%$ group and HbA1c $7.0 \%-7.9 \%$ group ( $<<0.001$ and $p<0.001$, respectively; online supplemental figure 2A). There was no significant difference in FMD between the HbA1c $<6.5 \%$ group and $\mathrm{HbA} 1 \mathrm{c} \geq 8.0 \%$ group ( $\mathrm{p}=0.055$; online supplemental figure $2 \mathrm{~A})$. NID values were $10.6 \% \pm 5.9 \%$ in the 
A

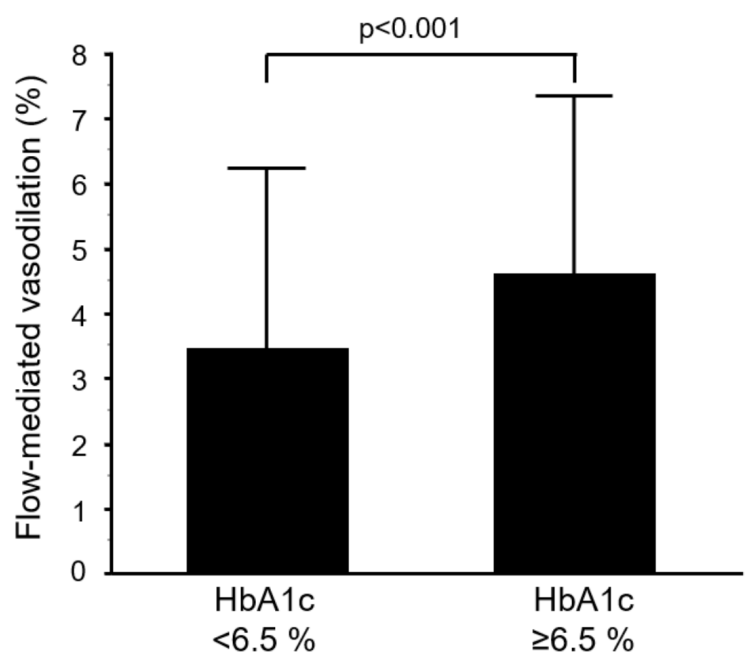

B

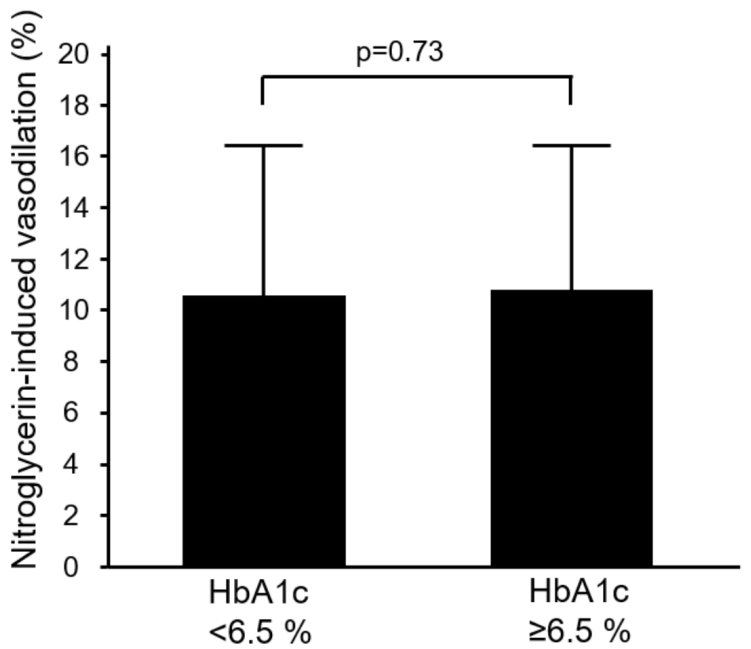

Figure 1 Bar graphs show flow-mediated vasodilation (A) and nitroglycerine-induced vasodilation $(B)$ in patients with $\mathrm{HbA} 1 \mathrm{c}<6.5 \%$ and patients with $\mathrm{HbA} 1 \mathrm{c} \geq 6.5 \%$. $\mathrm{HbA} 1 \mathrm{c}$, haemoglobin A1C.

HbAlc $<6.5 \%$ group, $11.2 \% \pm 5.4 \%$ in the HbA1c $6.5 \%-$ $6.9 \%$ group, $10.4 \% \pm 5.2 \%$ in the HbA1c $7.0 \%-7.9 \%$ group, and $10.4 \% \pm 6.8 \%$ in the HbAlc $\geq 8.0 \%$ group. There were no significant differences in NID values among the four groups ( $\mathrm{p}=0.82$; online supplemental figure $2 \mathrm{~B}$ ).

Univariate analysis of relationships among FMD, NID, HbA1c level and variables in patients with type 2 diabetes

Online supplemental table 2 shows the univariate relations among FMD, HbA1c level and variables. FMD was significantly correlated with age $(\mathrm{r}=-0.30, \mathrm{p}<0.001)$, diastolic blood pressure $(\mathrm{r}=0.17, \mathrm{p}<0.001)$, creatinine $(\mathrm{r}=-0.09$, $\mathrm{p}=0.002)$, HbAlc level $(\mathrm{r}=0.08, \mathrm{p}=0.004)$ and NID $(\mathrm{r}=0.33$, $\mathrm{p}<0.001)$. HbA1c level was significantly correlated with age $(\mathrm{r}=-0.21, \mathrm{p}<0.001)$, BMI $(\mathrm{r}=0.07, \mathrm{p}=0.01)$, systolic blood pressure $(\mathrm{r}=0.13, \mathrm{p}<0.001)$, diastolic blood pressure $(\mathrm{r}=0.14, \mathrm{p}<0.001)$, total cholesterol $(\mathrm{r}=0.18, \mathrm{p}<0.001)$, HDL cholesterol $(\mathrm{r}=-0.14, \mathrm{p}<0.001)$, low-density lipoprotein (LDL) cholesterol $(\mathrm{r}=0.16, \mathrm{p}<0.001)$, uric acid $(\mathrm{r}=-0.11, \quad \mathrm{p}<0.001)$, glucose level $(\mathrm{r}=0.57, \quad \mathrm{p}<0.001)$ and FMD $(r=0.08, p=0.004)$. Linear regression analysis revealed that $\mathrm{HbA1c}$ level was significantly correlated with FMD ( $r=0.08, p=0.004$; online supplemental figure 3A). A scatter plot between FMD and HbAlc level with a Lowess smoothed curve is shown in online supplemental figure 3B. FMD gradually increased with increase in $\mathrm{HbA1c}$ level to about $6.5 \%-6.9 \%$ and then decreased with increase in HbAlc level above $7.0 \%$.

Multivariate analysis of relationships among low quartile of FMD, low quartile of NID, low HbA1c level and variables

The division points for the lowest quartile and second quartile were $2.1 \%$ for FMD and $6.2 \%$ for NID. Therefore, we defined small FMD as FMD of $<2.1 \%$ and small NID as NID of $<6.2 \%$. We next examined whether low HbAlc (HbAlc $<6.5 \%$ ) was independently associated with small FMD by multiple logistic regression analysis. After adjustments for age, gender, BMI, current smoking, creatinine, and presence of hypertension, dyslipidaemia and $\mathrm{CVD}, \mathrm{HbAlc}<6.5 \%$ was independently associated with a lower quartile of FMD (OR: 2.03, 95\% CI 1.53 to 2.69 ; $\mathrm{p}<0.001)$ but was not associated with a lower quartile of NID (OR: $1.07,95 \%$ CI 0.65 to 1.75 ; $\mathrm{p}=0.80$ ) (online supplemental table 3 ).

Relationships among FMD, NID and HbA1c levels in patients with type 2 diabetes determined by using propensity score matching analysis

Propensity score matching analysis was used to create matched pairs between the HbA1c $<6.5 \%$ group and the other three groups (HbAlc 6.5\%-6.9\%, HbAlc 7.0\%-7.9\% and $\mathrm{HbAlc} \geq 8.0 \%$ ). The baseline characteristics of matched pairs of the low HbAlc level (HbAlc $<6.5 \%$ ) group and the other three groups are summarised in online supplemental tables 4-6. FMD was significantly smaller in the HbAlc $<6.5 \%$ group than in the HbAlc $6.5 \%-6.9 \%$ group and the HbAlc $7.0 \%-7.9 \%$ group $(3.8 \% \pm 2.6 \%$ vs $4.7 \% \pm 3.0 \%, \mathrm{p}=0.002$; $3.9 \% \pm 2.6 \%$ vs $4.5 \% \pm 2.6 \%, \mathrm{p}=0.04$; online supplemental figure $4 \mathrm{~A}, \mathrm{C})$, while there was no significant difference in FMD between the HbAlc $<6.5 \%$ group and the $\mathrm{HbAlc} \geq 8.0 \%$ group $(4.5 \% \pm 2.7 \%$ vs $4.1 \% \pm 2.8 \%, \mathrm{p}=0.36$; online supplemental figure $4 \mathrm{E})$. There were no significant differences in NID between the HbA1c $<6.5 \%$ group and the other three groups $(11.0 \% \pm 6.0 \%$ vs $11.2 \% \pm 5.5 \%$ in the HbAlc $<6.5 \%$ group vs the HbA1c $6.5 \%-6.9 \%$ group, $\mathrm{p}=0.84 ; 10.2 \% \pm 5.8 \%$ vs $10.5 \% \pm 5.6 \%$ in the HbAlc $<6.5 \%$ group vs the HbAlc $7.0 \%-7.9 \%$ group, $\mathrm{p}=0.82 ; 12.8 \% \pm 6.2 \%$ vs $11.6 \% \pm 7.2 \%$, in the HbAlc $<6.5 \%$ group vs the HbAlc $\geq 8.0 \%$ group, $\mathrm{p}=0.52$; online supplemental figure 4B,D,F).

\section{Study 2}

Baseline characteristics of patients with type 2 diabetes who were not taking antidiabetic drugs

Next, we evaluated the relationship between HbA1c level and FMD in patients with type 2 diabetes who were not taking antidiabetic drugs in order to eliminate possible effects of antidiabetic drugs and antidiabetic drug-induced hypoglycaemia on vascular function. The 
Table 2 Clinical characteristics of patients with type 2 diabetes not taking antidiabetic drugs according to HbA1c level

\begin{tabular}{|c|c|c|c|c|c|c|}
\hline Variables & $\begin{array}{l}\text { Total } \\
(n=349)\end{array}$ & $\begin{array}{l}\text { HbA1c } \\
<6.5 \% \\
(n=101)\end{array}$ & $\begin{array}{l}\text { HbA1c } \\
6.5 \%-6.9 \% \\
(n=149)\end{array}$ & $\begin{array}{l}\text { HbA1c } \\
7.0 \%-7.9 \% \\
(n=67)\end{array}$ & $\begin{array}{l}\text { HbA1c } \\
\geq 8.0 \% \\
(n=32)\end{array}$ & $P$ value \\
\hline Age, years & $61 \pm 10$ & $66 \pm 10$ & $60 \pm 10$ & $61 \pm 9$ & $57 \pm 10$ & $<0.001$ \\
\hline Gender, male/female & $245 / 104$ & $59 / 42$ & $108 / 41$ & $52 / 15$ & $26 / 6$ & 0.01 \\
\hline Body mass index, $\mathrm{kg} / \mathrm{m}^{2}$ & $25.4 \pm 4.2$ & $24.6 \pm 4.1$ & $25.5 \pm 4.2$ & $26.0 \pm 4.6$ & $25.8 \pm 4.2$ & 0.1 \\
\hline Heart rate, bpm & $69 \pm 11$ & $70 \pm 11$ & $68 \pm 11$ & $68 \pm 10$ & $69 \pm 11$ & 0.21 \\
\hline Systolic blood pressure, $\mathrm{mm} \mathrm{Hg}$ & $133 \pm 17$ & $128 \pm 18$ & $133 \pm 16$ & $136 \pm 16$ & $138 \pm 19$ & 0.004 \\
\hline Diastolic blood pressure, $\mathrm{mm} \mathrm{Hg}$ & $80 \pm 11$ & $77 \pm 12$ & $81 \pm 10$ & $82 \pm 10$ & $83 \pm 10$ & 0.002 \\
\hline Total cholesterol, mg/dL & $199 \pm 39$ & $186 \pm 33$ & $205 \pm 36$ & $197 \pm 45$ & $216 \pm 45$ & $<0.001$ \\
\hline Triglycerides, mg/dL & $169 \pm 139$ & $133 \pm 82$ & $169 \pm 143$ & $205 \pm 173$ & $206 \pm 162$ & 0.003 \\
\hline $\mathrm{HDL}-\mathrm{C}, \mathrm{mg} / \mathrm{dL}$ & $54 \pm 15$ & $57 \pm 15$ & $55 \pm 16$ & $48 \pm 12$ & $49 \pm 12$ & $<0.001$ \\
\hline LDL-C, mg/dL & $116 \pm 32$ & $110 \pm 30$ & $119 \pm 31$ & $115 \pm 36$ & $127 \pm 30$ & 0.04 \\
\hline Creatinine, mg/dL & $0.8 \pm 0.3$ & $0.8 \pm 0.4$ & $0.8 \pm 0.2$ & $0.8 \pm 0.2$ & $0.8 \pm 0.3$ & 0.33 \\
\hline Uric acid, mg/dL & $5.8 \pm 1.5$ & $6.0 \pm 1.7$ & $5.8 \pm 1.5$ & $5.5 \pm 1.4$ & $5.5 \pm 1.7$ & 0.23 \\
\hline Glucose, mg/dL & $137 \pm 46$ & $119 \pm 28$ & $125 \pm 22$ & $145 \pm 36$ & $224 \pm 78$ & $<0.001$ \\
\hline $\mathrm{HbA1c}, \%$ & $6.8 \pm 1.0$ & $5.9 \pm 0.4$ & $6.7 \pm 0.1$ & $7.3 \pm 0.3$ & $9.4 \pm 1.2$ & $<0.001$ \\
\hline \multicolumn{7}{|l|}{ Medical history, $\mathrm{n}(\%)$} \\
\hline Hypertension & 266 (76.2) & $75(74.3)$ & $112(75.2)$ & $56(83.6)$ & $23(71.9)$ & 0.45 \\
\hline Dyslipidaemia & $275(78.8)$ & 79 (78.2) & $116(77.9)$ & $57(85.1)$ & $23(71.9)$ & 0.46 \\
\hline CVD, n (\%) & 79 (22.6) & $27(26.7)$ & $29(19.5)$ & $17(25.4)$ & $6(18.8)$ & 0.50 \\
\hline Current smoking, n (\%) & 79 (22.6) & $20(19.8)$ & $34(23.3)$ & $17(25.4)$ & $8(26.7)$ & 0.79 \\
\hline \multicolumn{7}{|l|}{ Medication, n (\%) } \\
\hline Antihypertensive drugs & $217(62.2)$ & 78 (77.2) & $85(57.1)$ & $41(61.2)$ & $13(40.6)$ & $<0.001$ \\
\hline Lipid-lowering drugs & $144(41.3)$ & $59(58.4)$ & $57(38.3)$ & $24(35.8)$ & $4(12.5)$ & $<0.001$ \\
\hline Antidiabetic drugs & $0(0)$ & & & & & \\
\hline
\end{tabular}

bpm, beats per minute; CVD, cardiovascular disease; HbA1c, haemoglobin A1c; HDL-C, high-density lipoprotein cholesterol; LDL-C, lowdensity lipoprotein cholesterol.

baseline characteristics of those patients are summarised in table 2. The mean FMD value was $4.2 \% \pm 2.8 \%$ and the mean NID value was $10.6 \% \pm 5.8 \%$.

Relationships among HbA1c level, FMD, NID and variables in patients with type 2 diabetes who were not taking antidiabetic drugs with $\mathrm{HbA} 1 \mathrm{c}$ level $<6.5 \%$ and $\mathrm{HbA} 1 \mathrm{c}$ level $\geq 6.5 \%$

The baseline characteristics of patients with type 2 diabetes not taking antidiabetic drugs who had HbA1c level $<6.5 \%$ and HbAlc level $\geq 6.5 \%$ are summarised in online supplemental table 7. FMD was significantly smaller in the HbA1c $<6.5 \%$ group than in the HbA1c $\geq 6.5 \%$ group $(3.2 \% \pm 2.9 \%$ and $4.8 \% \pm 2.7 \%$, respectively, $\mathrm{p}<0.001$; online supplemental figure 5A). NID values were similar in the two groups $(11.0 \% \pm 6.0 \%$ in the $\mathrm{HbA} 1 \mathrm{c}<6.5 \%$ group and $11.3 \% \pm 4.7 \%$ in the HbA1c $\geq 6.5 \%$ group, $\mathrm{p}=0.79$; online supplemental figure $5 \mathrm{~B}$ ).

Next, the patients were divided into four groups according to HbA1c level: $<6.5 \%, 6.5 \%-6.9 \%, 7.0 \%-7.9 \%$ and $\geq 8.0 \%$. The baseline characteristics are summarised in table 2. FMD values were $3.2 \% \pm 2.9 \%$ in the HbAlc $<6.5 \%$ group, $5.2 \% \pm 2.9 \%$ in the HbAlc $6.5 \%-6.9 \%$ group, $4.4 \% \pm 2.4 \%$ in the HbAlc $7.0 \%-7.9 \%$ group, and $3.9 \% \pm 2.5 \%$ in the HbAlc $\geq 8.0 \%$ group $(\mathrm{p}<0.001$; figure 2A). FMD was significantly smaller in the HbA1c $<6.5 \%$ group than in the HbA1c $6.5 \%-6.9 \%$ group and HbA1c $7.0 \%-7.9 \%$ group, while there was no significant difference in FMD between the HbA1c $<6.5 \%$ group and the HbAlc $\geq 8.0 \%$ group $(\mathrm{p}<0.001, \mathrm{p}=0.02$ and $\mathrm{p}=0.62$, respectively; figure $2 \mathrm{~A}$ ). NID values were $11.0 \% \pm 6.0 \%$ in the HbA1c $<6.5 \%$ group, $12.6 \% \pm 3.7 \%$ in the HbA1c $6.5 \%-6.9 \%$ group, $10.1 \% \pm 5.7 \%$ in the $\mathrm{HbA1c} 7.0 \%-7.9 \%$ group, and $10.5 \% \pm 4.0 \%$ in the $\mathrm{HbAlc} \geq 8.0 \%$ group. There were no significant differences in NID values among the four groups $(\mathrm{p}=0.59$; figure $2 \mathrm{~B})$.

Univariate analysis of relationships among FMD, NID, HbA1c level and variables in patients with type 2 diabetes who were not taking antidiabetic drugs

Online supplemental table 8 shows the univariate relationships among FMD, HbA1c level and variables. FMD was significantly correlated with age $(r=-0.24, p<0.001)$, systolic blood pressure $(\mathrm{r}=0.10, \mathrm{p}=0.048)$, diastolic blood pressure $(\mathrm{r}=0.19, \mathrm{p}=0.02)$ and NID $(\mathrm{r}=0.36, \mathrm{p}<0.001)$. 
A

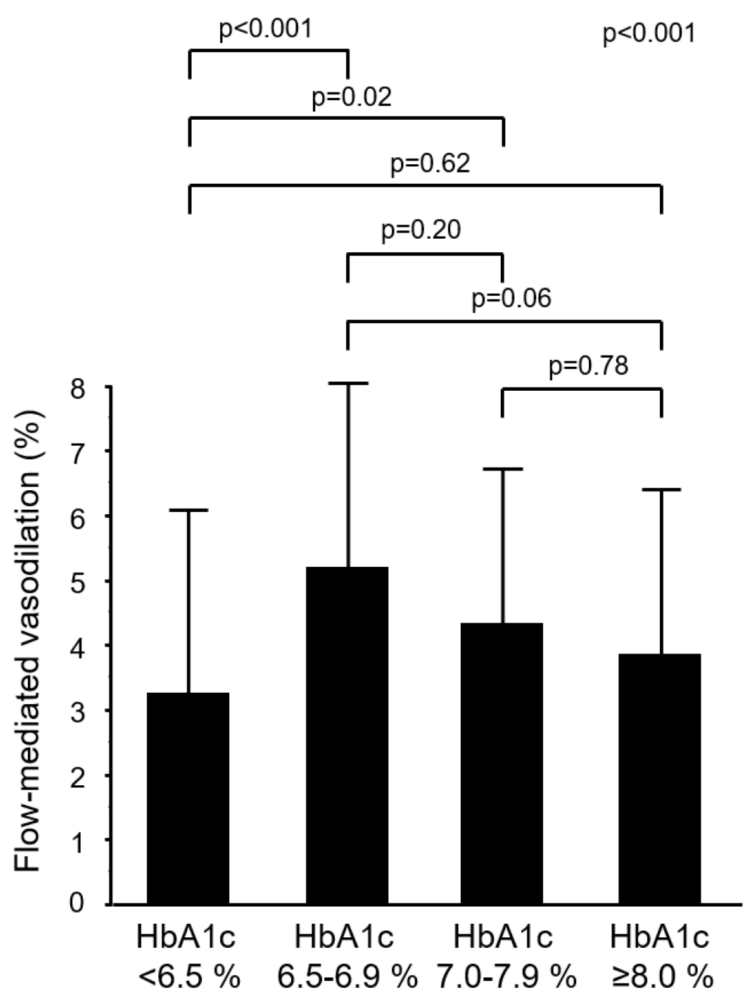

B

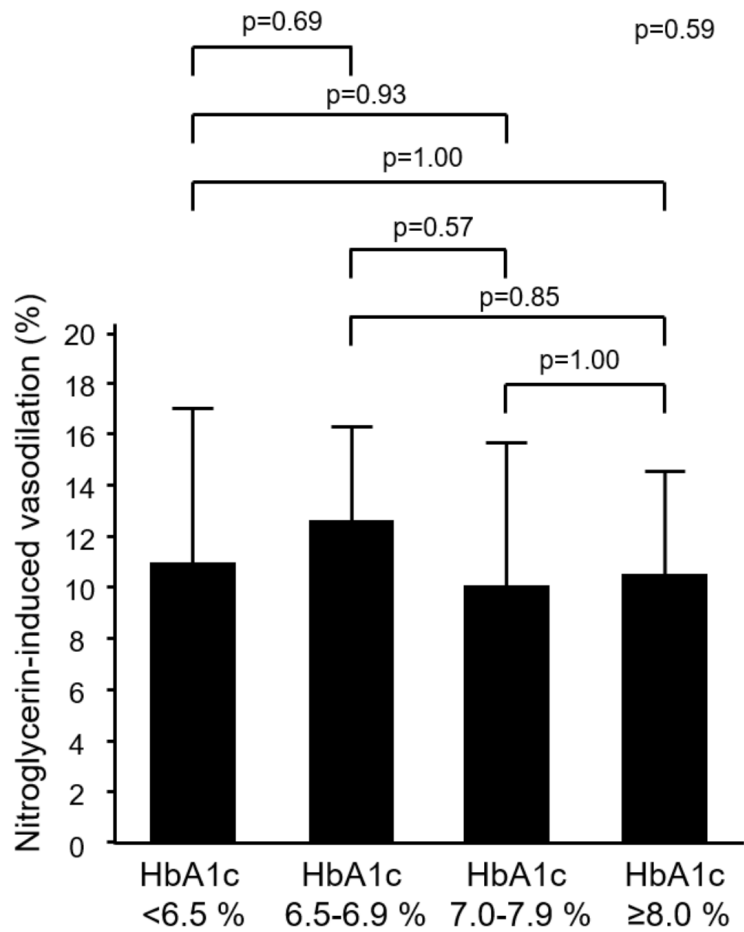

Figure 2 Bar graphs show flow-mediated vasodilation (A) and nitroglycerine-induced vasodilation (B) in four groups according to $\mathrm{HbA1c}$ level for patients not receiving antidiabetic drug treatment. HbA1c, haemoglobin A1c.

HbA1c level was significantly correlated with age $(r=-0.2$, $\mathrm{p}<0.001)$, systolic blood pressure $(\mathrm{r}=0.17, \mathrm{p}=0.001)$, diastolic blood pressure $(r=0.12, p=0.02)$, total cholesterol $(\mathrm{r}=0.22, \mathrm{p}<0.001)$, triglycerides $(\mathrm{r}=0.23, \mathrm{p}<0.001)$, HDL cholesterol $(\mathrm{r}=-0.19, \mathrm{p}<0.001)$, LDL cholesterol $(\mathrm{r}=0.14$, $\mathrm{p}=0.01)$ and glucose level $(\mathrm{r}=0.70, \mathrm{p}<0.001)$. Linear regression analysis revealed that $\mathrm{HbAlc}$ level was not significantly correlated with FMD $(r=0.05, p=0.40$; online supplemental figure $6 \mathrm{~A}$ ). Scatter plots between FMD and HbAlc with a Lowess smoothed curve are shown in online supplemental figure 6B. FMD gradually increased with increase in HbAlc level to about $6.5 \%-6.9 \%$ and then decreased with increase in HbAlc level above $7.0 \%$.

Multivariate analysis of relationships among low quartile of FMD, low quartile of NID, low $\mathrm{HbA} 1 \mathrm{c}$ level and variables in patients with type 2 diabetes who were not taking antidiabetic drugs

Multiple logistic regression analysis revealed that after adjustments for age, gender, BMI, current smoking, creatinine, and presence of hypertension, dyslipidaemia and CVD, HbAlc level $<6.5 \%$ was independently associated with a lower quartile of FMD (OR: 2.57, 95\% CI 1.45 to 4.54; $\mathrm{p}=0.001$ ), but was not associated with a lower quartile of NID (OR: 1.29 , 95\% CI 0.43 to 3.91 ; $\mathrm{p}=0.65$ ) (table 3).

Relationships among FMD, NID and HbA1c level in patients with type 2 diabetes who were not taking antidiabetic drugs determined by using propensity score matching analysis

Propensity score matching analysis was used to create matched pairs between the $\mathrm{HbAlc}<6.5 \%$ group and the other groups (HbA1c 6.5\%-6.9\%, HbAlc 7.0\%-7.9\% and HbAlc of $\geq 8.0 \%)$. The baseline characteristics of matched pairs of the low HbA1c level $<6.5 \%$ group and the other three groups are summarised in online supplemental tables 9-11. FMD was significantly smaller in the $\mathrm{HbAlc}<6.5 \%$ group than in the HbA1c $6.5 \%-6.9 \%$ group $(3.1 \% \pm 2.7 \%$ vs $4.6 \% \pm 3.2 \%, p=0.02$; online supplemental figure 7A), while there were no significant differences in FMD between the HbA1c $<6.5 \%$ group, the HbA1c $7.0 \%-$ $7.9 \%$ group and the $\mathrm{HbAlc} \geq 8.0 \%$ group $(3.2 \% \pm 3.2 \%$ vs $4.0 \% \pm 2.8 \%, \mathrm{p}=0.35 ; 4.0 \% \pm 3.0 \%$ vs $3.8 \% \pm 2.4 \%, \mathrm{p}=0.87$; online supplemental figure $7 \mathrm{C}$,E). There were no significant differences in NID between the HbA1c $<6.5 \%$ group and the other three groups $(10.8 \% \pm 5.6 \%$ vs $11.7 \% \pm 4.0 \%$ in the HbAlc $<6.5 \%$ group vs the HbAlc $6.5 \%-6.9 \%$ group, $\mathrm{p}=0.62 ; 11.8 \% \pm 5.7 \%$ vs $7.8 \% \pm 4.9 \%$ in the HbAlc $<6.5 \%$ group vs the HbAlc $7.0 \%-7.9 \%$ group, $\mathrm{p}=0.10$; $14.8 \% \pm 5.5 \%$ vs $13.6 \% \pm 3.9 \%$ in the $\mathrm{HbAlc}<6.5 \%$ group vs the $\mathrm{HbA1c} \geq 8.0 \%$ group, $\mathrm{p}=0.78$; online supplemental figure $7 \mathrm{~B}, \mathrm{D}, \mathrm{F})$.

\section{DISCUSSION}

In the present study, we demonstrated that a low HbAlc level of $<6.5 \%$ was independently associated with small FMD in patients with type 2 diabetes. After adjustments for confounding factors, FMD was significantly smaller in the HbA1c $<6.5 \%$ group than in the HbAlc $6.5 \%-6.9 \%$ group and $\mathrm{HbAlc} 7.0 \%-7.9 \%$ group. In patients who were not taking antidiabetic drugs, FMD was also significantly 
Table 3 Multivariate analysis of relationships among FMD, NID and low $\mathrm{HbA} 1 \mathrm{c}$ level $(<6.5 \%)$ in patients with type 2 diabetes not taking antidiabetic drugs

\begin{tabular}{lllll}
\hline & Low quartile of FMD & & Low quartile of NID \\
\cline { 2 - 3 } Variables & OR $(\mathbf{9 5 \%} \mathbf{~ C l})$ & P value & OR (95\% Cl) & $1.33(0.54$ to 3.31$)$ \\
\hline Model 1 & $3.05(1.80$ to 5.14$)$ & $<0.001$ & $1.20(0.46$ to 3.13$)$ & 0.53 \\
Model 2 & $2.49(1.44$ to 4.33$)$ & 0.001 & $1.29(0.43$ to 3.91$)$ & 0.71 \\
Model 3 & $2.57(1.45$ to 4.54$)$ & 0.001 & 0.65 \\
\hline
\end{tabular}

Model 1: unadjusted model.

Model 2: adjusted for age, gender and body mass index.

Model 3: adjusted for age, gender, body mass index, current smoking, creatinine, presence of hypertension, dyslipidaemia and CVD. Low quartile of FMD indicates less than 2.1\%. Low quartile of NID indicates less than $6.2 \%$.

CVD, cardiovascular disease; FMD, flow-mediated vasodilation; HbA1c, haemoglobin A1c; NID, nitroglycerine-induced vasodilation.

smaller in the HbA1c $<6.5 \%$ group than in the HbA1c $6.5 \%-6.9 \%$ group and $\mathrm{HbA} 1 \mathrm{c} 7.0 \%-7.9 \%$ group. We also confirmed by using propensity score matching analysis that FMD was significantly smaller in the low HbA1c group than in the HbA1c $6.5 \%-6.9 \%$ group. To our knowledge, the present study is the first study showing detailed relationships between HbA1c level and endothelial function in patients with type 2 diabetes, including patients not taking antidiabetic drugs.

Interestingly, in the present study, HbAlc levels were not correlated with NID. There were no significant differences in NID values among the HbAlc groups of $<6.5 \%$, $6.5 \%-6.9 \%, 7.0 \%-7.9 \%$ and $\geq 8.0 \%$. In patients with type 2 diabetes who were not taking antidiabetic drugs, there were also no significant differences in NID values among the four groups. These findings suggest that HbA1c level is not correlated with vascular smooth muscle function.

It is controversial whether endothelium-independent vasodilation assessed by NID as well as endotheliumdependent vasodilation assessed by FMD are impaired in individuals with cardiovascular risk factors and patients with CVD. ${ }^{24}{ }^{25}$ In the present study, although we found that there was an inverted U-shaped pattern of association between FMD and HbA1c, there was no significant relationship between NID and HbAlc. In a previous study, we showed that both NID and FMD were maintained in subjects without cardiovascular risk factors and that FMD was significantly smaller in subjects with cardiovascular risk factors than in subjects without cardiovascular risk factors, but that NID was significantly smaller in patients with CVD than in both subjects with and those without cardiovascular risk factors, whereas there was no significant difference in NID between subjects with and those without cardiovascular risk factors, suggesting that FMD values and NID values are different in relation to the grade of atherosclerosis. ${ }^{23}$ The Hoorn Study showed that although FMD was significantly smaller in patients with type 2 diabetes than in subjects with normal glucose metabolism, NID values were similar in the two groups. ${ }^{26}$ Kubota et $a 2^{27}$ showed that NID did not alter after treatment with sitagliptin in patients with type 2 diabetes and that changes in NID did not correlate with changes in $\mathrm{HbAlc}$, while FMD improved in relation to decrease in HbA1c. These previous studies support our results showing that NID is not associated with HbA1c levels in patients with type 2 diabetes.

It is well known that the incidence of myocardial infarction increases in relation to HbAlc level. ${ }^{28}$ It is thought that FMD, an index of endothelial function, decreases with increase in HbAlc level. However, in the present study, a low HbA1c level of $<6.5 \%$ was found to be independently associated with endothelial dysfunction in patients with type 2 diabetes. To avoid the effects of antidiabetic drugs on HbA1c levels and to minimise the effect of hypoglycaemia, we evaluated the relationship between HbAlc level and FMD in patients with type 2 diabetes who were not taking antidiabetic drugs, and we found that the results were similar for patients taking and those not taking antidiabetic drugs.

The key finding of this study was that an inverted U-shaped pattern of association between HbAlc and FMD was observed at the peak of $\mathrm{HbA1c}$ of about $7 \%$ in patients with type 2 diabetes. This result may reflect the existence of a J-curve pattern of association between HbAlc and all causes of mortality. Diabetes is well known as a risk factor for endothelial function as well as for CVD. ${ }^{15} 2629$ However, the effect of intensive glucose control therapy on all causes of mortality is still controversial. Previous studies focused on the relationship between $\mathrm{HbA1c}$ and all causes of mortality. Some studies showed a positive linear relationship between $\mathrm{HbA1c}$ and all causes of mortality, ${ }^{30}$ while other studies showed a J-shaped relationship between HbA1c and all causes of mortality. ${ }^{3233}$ The effects of intensive glucose control therapy on morbidity and mortality of cardiovascular events are also controversial. $^{33}$ TheUnited Kingdom Prospective Diabetes Study (UKPDS) 73 study showed that the frequency of hypoglycaemia in patients not taking antidiabetic drugs was $0.1 \%{ }^{35}$ Hypoglycaemia during intensive glucose control is probably a predictor of morbidity and mortality of cardiovascular events. It has been shown that the HRs for all causes of mortality including cardiovascular events in patients with severe hypoglycaemia episodes are between 1.74 and 3.27. ${ }^{36} 37$ It has been postulated that hypoglycaemia activates the sympathetic nervous system, resulting in release of catecholamines that cause increases in heart 
rate and myocardial contractility, ${ }^{38}$ and activates platelet aggregation, leading to acute coronary syndrome and fatal arrhythmia. ${ }^{39}$ Although the precise mechanism by which a low HbAlc level impairs endothelial function is uncertain, activation of the sympathetic nervous system may play a critical role in endothelial dysfunction. We cannot deny the possibility that factors other than hypoglycaemia contribute to low HbAlc-induced endothelial dysfunction.

This study has some limitations. First, this study was a cross-sectional study, although it was conducted in multiple centres and had a large sample size. Therefore, we were able to evaluate the association but not causality between low HbA1c level and FMD. Second, unfortunately, we did not have information on the duration of diabetes from onset. The UKPDS 80 study has shown that CVD risk reduction was observed after 10 years of follow-up of intensive glucose therapy in patients with newly diagnosed type 2 diabetes. Assessment of information on duration of diabetes would enable more specific conclusions concerning the role of HbAlc in endothelial function to be drawn. Third, this study was conducted in Japan, and our results on the association between HbAlc and FMD might not be applicable to other races. However, the ACCORD trial was conducted in North America, and the ADVANCE trial was conducted in 20 countries including countries in Asia and Europe and in North America and Australia. The results of those studies suggest that an inverted U-shaped pattern of association between FMD and HbA1c, which was found in the present study, exists in all races. It is well known that HbA1c levels do not accurately reflect mean glucose values in patients with end-stage chronic kidney disease and in patients on dialysis. In the present study, we excluded those patients and we adjusted serum creatinine levels using propensity score matching analysis. Fourth, we did not have information on physical activity. Previous studies have shown that lifestyle per se and lifestyle modifications such as diet and physical activity influence endothelial function. ${ }^{40-42}$ Assessment of the status of physical activity would enable more specific conclusions concerning the role of HbAlc in endothelial function to be drawn. Fifth, it is well known that hypertensive drugs, lipid-lowering drugs and antidiabetic drugs affect vascular function. Therefore, on the examination day, measurements of FMD and NID were conducted in the morning, all medications were withheld, and only drinking water was given to the patients. Patients in this study with $\mathrm{HbA1c}<6.5 \%$ had been taking large doses of antihypertensive drugs, lipid-lowering drugs and antidiabetic drugs. Unfortunately, we had no information on the kinds of drugs that were used in this study population. Therefore, we matched information on medications by propensity matched analysis. Even after adjustment for information on medications, patients with HbA1c $<6.5 \%$ had lower FMD levels than did patients with $\mathrm{HbA1c} \geq 6.5 \%$. However, we cannot deny the possibility that differences in pharmacological interventions affected vascular function in this study population. In addition, since elderly patients often have malnutrition due to anorexia, which leads to low $\mathrm{HbAlc}$, we excluded patients over 80 years of age. Even after excluding these confounding factors, a low $\mathrm{HbA1c}$ level was associated with endothelial dysfunction in patients with type 2 diabetes.

In conclusions, there is an inverted U-shaped pattern of association between FMD and HbAlc and a low HbA1c level $(<6.5 \%)$ is associated with endothelial dysfunction in patients with type 2 diabetes, even in patients with type 2 diabetes who are not taking antidiabetic drugs.

\section{Author affiliations}

${ }^{1}$ Department of Cardiovascular Medicine, Hiroshima University Faculty of Medicine Graduate School of Biomedical and Health Sciences, Hiroshima, Japan ${ }^{2}$ Division of Regeneration and Medicine, Medical Center for Translational and Clinical Research, Hiroshima University Hospital, Hiroshima, Japan

${ }^{3}$ Department of Cardiovascular Regeneration and Medicine, Hiroshima University Research Institute for Radiation Biology and Medicine, Hiroshima, Japan

${ }^{4}$ Graduate School of Medicine Department of Biostatistics and Data Science, Osaka University, Suita, Japan

${ }^{5}$ Department of Gastroenterology and Metabolism, Hiroshima University Faculty of Medicine Graduate School of Biomedical and Health Sciences, Hiroshima, Japan ${ }^{6}$ Department of Rehabilitation, Hiroshima International University, Higashihiroshima, Japan

${ }^{7}$ Department of Stem Cell Biology and Medicine, Hiroshima University Faculty of Medicine Graduate School of Biomedical and Health Sciences, Hiroshima, Japan

Acknowledgements The authors would like to thank all of the patients who participated in this study. In addition, we thank Miki Kumiji, Megumi Wakisaka, Ki-ichiro Kawano and Satoko Michiyama for their excellent secretarial assistance; FMD-J investigators Takayuki Hidaka, MD, PhD; Shuji Nakamura, MD, PhD; Junko Soga, MD, PhD; Yuichi Fujii, MD, PhD; Naomi Idei, MD; Noritaka Fujimura, MD, PhD; Shinsuke Mikami, MD, PhD; Yumiko Iwamoto, MD; Akimichi Iwamoto, MD, PhD; Takeshi Matsumoto, MD, PhD; Nozomu Oda, MD, PhD (Department of Cardiovascular Medicine, Hiroshima University Graduate School of Biomedical Sciences, Hiroshima, Japan); Kana Kanai, PhD; Haruka Morimoto, PhD (Department of Cardiovascular Regeneration and Medicine, Research Institute for Radiation Biology and Medicine, Hiroshima University, Hiroshima, Japan); Tomohisa Sakashita, MD, PhD; Yoshiki Kudo, MD, PhD (Department of Obstetrics and Gynecology, Hiroshima University Graduate School of Biomedical Sciences, Hiroshima, Japan); Taijiro Sueda, MD, PhD (Department of Surgery, Hiroshima University Graduate School of Biomedical Sciences, Hiroshima, Japan); Hirofumi Tomiyama, MD, $\mathrm{PhD}$, FAHA; Akira Yamashina, MD, PhD (Department of Cardiology, Tokyo Medical University, Tokyo, Japan); Bonpei Takase, MD, PhD, FAHA (Division of Biomedical Engineering, National Defense Medical College Research Institute, Tokorozawa, Japan); Takahide Kohro, MD, PhD (Department of Cardiology, Tokyo Medical University, Tokyo, Japan); Toru Suzuki, MD, PhD (Cardiovascular Medicine, University of Leicester, Leicester, UK); Tomoko Ishizu, MD, PhD (Cardiovascular Division, Institute of Clinical Medicine, University of Tsukuba, Ibaraki, Japan); Shinichiro Ueda, MD, PhD (Department of Clinical Pharmacology and Therapeutics, University of the Ryukyus School of Medicine, Okinawa, Japan); Tsutomu Yamazaki, MD, $\mathrm{PhD}$ (Clinical Research Support Center, Faculty of Medicine, University of Tokyo, Tokyo, Japan); Tomoo Furumoto, MD, PhD (Department of Cardiovascular Medicine, Hokkaido University Graduate School of Medicine, Hokkaido, Japan); Kazuomi Kario, MD, PhD (Division of Cardiovascular Medicine, Jichi Medical University School of Medicine, Tochigi, Japan); Teruo Inoue, MD, PhD (Department of Cardiovascular Medicine, Dokkyo Medical University, Mibu, Tochigi, Japan); Shinji Koba, MD, PhD (Department of Medicine, Division of Cardiology, Showa University School of Medicine, Tokyo, Japan); Kentaro Watanabe, MD, PhD (Department of Neurology, Hematology, Metabolism, Endocrinology and Diabetology (DNHMED), Yamagata University School of Medicine, Yamagata, Japan); Yasuhiko Takemoto, MD, PhD (Department of Internal Medicine and Cardiology, Osaka City University Graduate School of Medicine, Osaka, Japan); Takuzo Hano, MD, PhD (Department of Medical Education and Population-based Medicine, Postgraduate School of Medicine, Wakayama Medical University, Wakayama, Japan); Masataka Sata, MD, $\mathrm{PhD}$ (Department of Cardiovascular Medicine, Institute of Health Biosciences, University of Tokushima Graduate School, Tokushima, Japan); Yutaka Ishibashi, MD, $\mathrm{PhD}$ (Department of General Medicine, Shimane University Faculty of Medicine, 
Izumo, Japan); Koichi Node, MD, PhD (Department of Cardiovascular and Renal Medicine, Saga University, Saga, Japan); Koji Maemura, MD, PhD (Department of Cardiovascular Medicine, Nagasaki University Graduate School of Biomedical Sciences, Nagasaki, Japan); Yusuke Ohya, MD, PhD (Third Department of Internal Medicine, University of the Ryukyus, Okinawa, Japan); Taiji Furukawa, MD, PhD (Department of Internal Medicine, Teikyo University School of Medicine, Tokyo, Japan); Hiroshi Ito, MD, PhD (Department of Cardiovascular Medicine, Okayama University Graduate School of Medicine, Dentistry and Pharmaceutical Sciences, Japan); and Hisao lkeda, MD, PhD (Faculty of Fukuoka Medical Technology, Teikyo University, Omuta, Japan).

Contributors TY and YHi: drafting the article and conception of the study. TH, YHas, YT, MK, YHan, TM, SK, HH, CG, AN and FMY: acquiring subjects and/or data. $\mathrm{EH}, \mathrm{KC}$ and $\mathrm{YK}$ : revising the article critically for important intellectual content. YHi is the guarantor of this work and as such had full access to all of the data in the study and takes responsibility for the integrity of the data and the accuracy of data analysis.

Funding Funding was received from Grant-in-Aid for Scientific Research from the Ministry of Education, Science and Culture of Japan (18590815 and 21590898 to YHi) and Grant-in-Aid of Japanese Arteriosclerosis Prevention Fund (to YHi).

\section{Competing interests None declared.}

Patient consent for publication Not required.

Ethics approval The protocol of this study conforms to the ethical guidelines of the 1975 Declaration of Helsinki and was approved by the ethical committee of Hiroshima University.

Provenance and peer review Not commissioned; externally peer reviewed.

Data availability statement Data are available upon reasonable request. There is no additional information.

Supplemental material This content has been supplied by the author(s). It has not been vetted by BMJ Publishing Group Limited (BMJ) and may not have been peer-reviewed. Any opinions or recommendations discussed are solely those of the author(s) and are not endorsed by BMJ. BMJ disclaims all liability and responsibility arising from any reliance placed on the content. Where the content includes any translated material, BMJ does not warrant the accuracy and reliability of the translations (including but not limited to local regulations, clinical guidelines, terminology, drug names and drug dosages), and is not responsible for any error and/or omissions arising from translation and adaptation or otherwise.

Open access This is an open access article distributed in accordance with the Creative Commons Attribution Non Commercial (CC BY-NC 4.0) license, which permits others to distribute, remix, adapt, build upon this work non-commercially, and license their derivative works on different terms, provided the original work is properly cited, appropriate credit is given, any changes made indicated, and the use is non-commercial. See: http://creativecommons.org/licenses/by-nc/4.0/.

\section{ORCID iD}

Yukihito Higashi http://orcid.org/0000-0001-5813-3672

\section{REFERENCES}

1 Standl E, Balletshofer B, Dahl B, et al. Predictors of 10-year macrovascular and overall mortality in patients with NIDDM: the Munich general practitioner project. Diabetologia 1996;39:1540-5.

2 Khaw K-T, Wareham N, Bingham S, et al. Association of hemoglobin A1c with cardiovascular disease and mortality in adults: the European prospective investigation into cancer in Norfolk. Ann Intern Med 2004;141:413-20.

3 Stamler J, Vaccaro O, Neaton JD, et al. Diabetes, other risk factors, and 12-yr cardiovascular mortality for men screened in the multiple risk factor intervention trial. Diabetes Care 1993;16:434-44.

4 ACCORD Study Group, ACCORD Eye Study Group, Chew EY, et al. Effects of medical therapies on retinopathy progression in type 2 diabetes. N Engl J Med 2010;363:233-44.

5 ADVANCE Collaborative Group, Patel A, MacMahon S, et al. Intensive blood glucose control and vascular outcomes in patients with type 2 diabetes. N Engl J Med 2008;358:2560-72.

6 Ohkubo Y, Kishikawa H, Araki E, et al. Intensive insulin therapy prevents the progression of diabetic microvascular complications in Japanese patients with non-insulin-dependent diabetes mellitus: a randomized prospective 6-year study. Diabetes Res Clin Pract 1995;28:103-17.
7 Duckworth W, Abraira C, Moritz T, et al. Glucose control and vascular complications in veterans with type 2 diabetes. N Engl J Med 2009;360:129-39.

8 Action to Control Cardiovascular Risk in Diabetes Study Group, Gerstein HC, Miller ME, et al. Effects of intensive glucose lowering in type 2 diabetes. N Engl J Med 2008;358:2545-59.

9 Higashi Y, Noma K, Yoshizumi M, et al. Endothelial function and oxidative stress in cardiovascular diseases. Circ J 2009;73:411-8.

10 Soga J, Noma K, Hata T, et al. Rho-Associated kinase activity, endothelial function, and cardiovascular risk factors. Arterioscler Thromb Vasc Biol 2011;31:2353-9.

11 Yeboah J, Folsom AR, Burke GL, et al. Predictive value of brachial flow-mediated dilation for incident cardiovascular events in a population-based study: the multi-ethnic study of atherosclerosis. Circulation 2009;120:502-9.

12 Yugar-Toledo JC, Tanus-Santos JE, Sabha M, et al. Uncontrolled hypertension, uncompensated type II diabetes, and smoking have different patterns of vascular dysfunction. Chest 2004;125:823-30.

13 Martens FMAC, Rabelink TJ, op 't Roodt J, et al. Tnf-Alpha induces endothelial dysfunction in diabetic adults, an effect reversible by the PPAR-gamma agonist pioglitazone. Eur Heart $J$ 2006;27:1605-9.

14 Higashi Y, Yoshizumi M. Exercise and endothelial function: role of endothelium-derived nitric oxide and oxidative stress in healthy subjects and hypertensive patients. Pharmacol Ther 2004;102:87-96.

15 Maruhashi T, Soga J, Fujimura N, et al. Relationship between flowmediated vasodilation and cardiovascular risk factors in a large community-based study. Heart 2013;99:1837-42.

16 Tacito LHB, Pires AC, Yugar-Toledo JC. Impaired flow-mediated dilation response and carotid intima-media thickness in patients with type 1 diabetes mellitus with a mean disease duration of 4.1 years. Arch Endocrinol Metab 2017;61:542-9.

17 Brownlee M. Biochemistry and molecular cell biology of diabetic complications. Nature 2001;414:813-20.

18 Nakamura K, Oe H, Kihara H, et al. Dpp-4 inhibitor and alphaglucosidase inhibitor equally improve endothelial function in patients with type 2 diabetes: edge study. Cardiovasc Diabetol 2014;13:110.

19 Moreno B, de Faria AP, Ritter AMV, et al. Glycated hemoglobin correlates with arterial stiffness and endothelial dysfunction in patients with resistant hypertension and uncontrolled diabetes mellitus. J Clin Hypertens 2018;20:910-7.

20 Tomiyama $\mathrm{H}$, Kohro T, Higashi $\mathrm{Y}$, et al. A multicenter study design to assess the clinical usefulness of semi-automatic measurement of flow-mediated vasodilatation of the brachial artery. Int Heart $J$ 2012;53:170-5

21 Expert Panel on Detection, Evaluation, and Treatment of High Blood Cholesterol in Adults. Executive summary of the third report of the National cholesterol education program (NCEP) expert panel on detection, evaluation, and treatment of high blood cholesterol in adults (adult treatment panel III). JAMA 2001;285:2486-97.

22 American Diabetes Association. 2. Classification and Diagnosis of Diabetes: Standards of Medical Care in Diabetes-2018. Diabetes Care 2018:41:S13-27.

23 Maruhashi T, Soga J, Fujimura N, et al. Nitroglycerine-induced vasodilation for assessment of vascular function: a comparison with flow-mediated vasodilation. Arterioscler Thromb Vasc Biol 2013;33:1401-8.

24 Iwamoto Y, Maruhashi T, Kajikawa M, et al. Chronic kidney disease is associated with vascular smooth muscle dysfunction but not with endothelial dysfunction. Int J Cardiol 2018;254:284-90.

25 Matsui S, Kajikawa M, Maruhashi T, et al. Decreased frequency and duration of tooth brushing is a risk factor for endothelial dysfunction. Int J Cardiol 2017;241:30-4.

26 Henry RMA, Ferreira I, Kostense PJ, et al. Type 2 diabetes is associated with impaired endothelium-dependent, flow-mediated dilation, but impaired glucose metabolism is not; the Hoorn study. Atherosclerosis 2004:174:49-56.

27 Kubota Y, Miyamoto M, Takagi G, et al. The dipeptidyl peptidase-4 inhibitor sitagliptin improves vascular endothelial function in type 2 diabetes. J Korean Med Sci 2012;27:1364-70.

28 Stratton IM, Adler Al, Neil HA, et al. Association of glycaemia with macrovascular and microvascular complications of type 2 diabetes (UKPDS 35): prospective observational study. BMJ 2000;321:405-12.

29 Williams SB, Cusco JA, Roddy MA, et al. Impaired nitric oxidemediated vasodilation in patients with non-insulin-dependent diabetes mellitus. J Am Coll Cardiol 1996;27:567-74.

30 Palta P, Huang ES, Kalyani RR, et al. Hemoglobin A and Mortality in Older Adults With and Without Diabetes: Results From the National Health and Nutrition Examination Surveys (1988-2011). Diabetes Care 2017;40:453-60. 
31 Sluik D, Boeing H, Montonen J, et al. Hba1C measured in stored erythrocytes is positively linearly associated with mortality in individuals with diabetes mellitus. PLOS One 2012;7:e38877.

32 Arnold LW, Wang Z. The HbA1c and all-cause mortality relationship in patients with type 2 diabetes is $\mathrm{J}$-shaped: a meta-analysis of observational studies. Rev Diabet Stud 2014;11:138-52.

33 Wan EYF, Fung CSC, Wong CKH, et al. Association of hemoglobin A1c levels with cardiovascular disease and mortality in Chinese patients with diabetes. J Am Coll Cardiol 2016;67:456-8.

34 Rawshani A, Rawshani A, Franzén S, et al. Risk factors, mortality, and cardiovascular outcomes in patients with type 2 diabetes. N Engl $J$ Med 2018;379:633-44.

35 Wright AD, Cull CA, Macleod KM, et al. Hypoglycemia in type 2 diabetic patients randomized to and maintained on monotherapy with diet, sulfonylurea, metformin, or insulin for 6 years from diagnosis: UKPDS73. J Diabetes Complications 2006;20:395-401.

36 Zoungas S, Patel A, Chalmers J, et al. Severe hypoglycemia and risks of vascular events and death. N Engl J Med 2010;363:1410-8.
37 ORIGIN Trial Investigators, Mellbin LG, Rydén L, et al. Does hypoglycaemia increase the risk of cardiovascular events? A report from the origin trial. Eur Heart $J$ 2013;34:3137-44.

38 Fisher BM, Gillen G, Hepburn DA, et al. Cardiac responses to acute insulin-induced hypoglycemia in humans. Am J Physiol 1990;258:H1775-9.

39 Wright RJ, Frier BM. Vascular disease and diabetes: is hypoglycaemia an aggravating factor? Diabetes Metab Res Rev 2008;24:353-63.

40 Sasaki S, Higashi Y, Nakagawa K, et al. A low-calorie diet improves endothelium-dependent vasodilation in obese patients with essential hypertension. Am J Hypertens 2002;15:302-9.

41 Higashi Y, Sasaki S, Sasaki N, et al. Daily aerobic exercise improves reactive hyperemia in patients with essential hypertension. Hypertension 1999;33:591-7.

42 Goto C, Higashi Y, Kimura M, et al. Effect of different intensities of exercise on endothelium-dependent vasodilation in humans: role of endothelium-dependent nitric oxide and oxidative stress. Circulation 2003;108:530-5. 